Chapman University

Chapman University Digital Commons

Philosophy Faculty Articles and Research

Science and Technology Faculty Articles and

Research

2020

Political Philosophy as Love of Wisdom

Bas van der Vossen

Follow this and additional works at: https://digitalcommons.chapman.edu/philosophy_articles

Part of the Ethics and Political Philosophy Commons 


\section{Political Philosophy as Love of Wisdom}

\section{Comments}

This is an Accepted Manuscript version of the following article, accepted for publication in Australasian Philosophical Review, volume 4, issue 1, in 2020. It is deposited under the terms of the Creative Commons Attribution-NonCommercial License (http://creativecommons.org/licenses/by-nc/4.0/), which permits non-commercial re-use, distribution, and reproduction in any medium, provided the original work is properly cited.

\section{Creative Commons License} (c) (1) (9)

This work is licensed under a Creative Commons Attribution-Noncommercial 4.0 License

\section{Copyright}

Taylor \& Francis 


\section{Political philosophy as love of wisdom}

Bas van der Vossen

During my last year as a graduate student at Oxford, I attended G.A. Cohen's retirement lecture. As so often with Cohen, it turned out to be not so much a lecture as a stand-up comedy routine. After two hours of jokes, Cohen ended his lecture on a serious note. Addressing the graduate students in the room, he urged us to remain aware of how lucky we are to live the life of a philosopher. For all its foibles, doing philosophy means doing something genuinely important: seeking the truth.

Cohen's remark made an impact. It was a rousing statement of purpose and value, a commitment to doing philosophy for the right reasons. And it was coming from someone whose philosophical positions I rejected. I accept neither Cohen's conclusion nor his way of arriving at them. Still, we are participants in the same enterprise - working together at trying to discover what's truly just.

Avner de Shalit wants to move away from this way of doing political philosophy. Philosophers should do their work in direct consultation with "the people." This consultation is supposed to be the starting point of a new philosophical method. The goal of political philosophy is not so much to seek the truth about political matters. Rather, it's to think through the public's theories about the political institutions under which they live.

Let's call Cohen's (and my) view of political philosophy the traditional view. I label it traditional because, since its inception, almost all philosophy has understood the task of philosophers to be the search of the truth. ${ }^{1}$ Political philosophy, as just one branch of philosophy more generally, then seeks the truth about politics. That can be understood in many different ways: one might ask what politics really is, what it represents, what it ought to be, and so on. But in all guises, the truth-oriented nature of the task is essential.

By orienting the discipline toward finding out what "the public's" views are, de Shalit proposes a departure from this traditional view. To him, philosophical theories should go "hand in hand with common public sentiment". De Shalit's underlying reason illustrates the divergence. As de Shalit sees things:

Political philosophy is about political persuasion that certain positions or certain political institutions are ethical or just.

De Shalit takes both the political and the persuading parts very seriously. Instead of finding out what principles and conclusions might be true, he holds that "political philosophy should [use] ... not only the public's intuitions but also the public's theories."

In what follows, I shall defend the traditional view, that political philosophy is just one kind of philosophy in general - a search for the (political) truth. I won't argue that such truth-seeking is

\footnotetext{
${ }^{1}$ Most philosophers do not even think to state it explicitly or defend it. For instance, in his recent book Doing Philosophy, Timothy Williamson mentions it only in passing, such as when he expresses that philosophy has the same aim as the natural sciences, namely "to answer the same questions about the underlying nature of reality." Timothy Williamson, Doing Philosophy, (Oxford University Press, 2018), p. 4
} 
the only goal that's appropriate for political philosophers. But I will argue that the goal is essential to what we do.

\section{Philosophy and public sentiment}

Consider again de Shalit's view that philosophical theories must go "hand in hand with common public sentiment." Does this proposal survive itself?

What about common public sentiment about how political philosophy is to be done? Lots of people seem to hold the traditional view of political philosophy I favor. (Do the people? More on that in a moment.) A theory of political philosophy that "goes hand in hand with common public sentiment" would then imply rejecting a view of political philosophy that "goes hand in hand with common public sentiment."

Of course, most likely "public sentiment" is divided on this issue. As it is on virtually every other philosophically interesting issue. What are we to make of that? The traditional view holds that it's the philosopher's job to investigate, in a principled and systematic way, which side (if any) is right. Indeed, it's our job to sort out what is right and true even in the case the public is not divided. After all, the public might (and often does) overwhelmingly support false views.

Socrates discussed philosophy in the streets, much like de Shalit wants us to do. But Socrates obviously did not think that the content of his views had to be sensitive to public sentiment. All he did was try to convince people they were wrong. The Athenian people, by contrast, backed up with death their demand that Socrates' theories remain in line with public sentiment.

What if things were different? Suppose the public thinks we should do what de Shalit wants. That wouldn't solve the issues above, but maybe we can live with that. Then again, why take this view of the public as authoritative for philosophical theory? After all, "the public" typically holds inconsistent views. Indeed, most individual people within the public hold inconsistent views. $^{2}$

This latter point is obvious, of course, and de Shalit recognizes it. But it's not clear he recognizes the problem it creates. For what is the follower of his proposal to do in light of such inconsistencies? It's complicated, to be sure, but one thing must be ruled out from the start. We cannot demand that our theories do not clash with "common public sentiment." The very fact that people have inconsistent views implies that any consistent theory will endorse a view that the public rejects.

We cannot figure out which parts of the overall inconsistent whole need to be rejected by reference to the public's inconsistent views, then. We need to appeal to some other, external standard. The truth seems the only acceptable one. (Wouldn't any other standard at least have to be a true standard?)

That's a good thing, too. Given that people hold inconsistent views, they hold views that are false. And since the public might be (is) mistaken about many important issues, it's a good idea to have people in our midst who make it their business to find out what's true about these issues. That business cannot take the public's views as its beginning or end.

\footnotetext{
2 Below I will show there is no such thing as "the public," at least not in the sense needed for de Shalit's position to work. But even if there were "a public", is there such a thing as "the public's" views? Those impressed with Arrow's theorem and related findings would demur. In any case, there are extremely difficult issues about how to aggregate these views in a way that makes de Shalit's proposal workable.
} 


\section{Democracy in philosophy}

De Shalit thinks the traditional view of philosophy is undemocratic. It does not fit with a political theory that generally prizes democracy. For such a theory must value "consulting the public."

De Shalit is right, of course, that the traditional search for the truth need not put much stock in the generally held views of people in society. It recognizes questions as important even if they do not animate the public right now. And it recognizes questions as important even if their answers run directly contrary to what the public wants or thinks.

Still, without argument, a mere appeal to democracy isn't convincing. If democracy is an ideal, the question remains what it's an ideal for? Believing in democracy as an ideal for politics doesn't mean believing in democracy as an ideal for every part of life. One need not consult "the people" when thinking about where to go for lunch, say.

Whether or not philosophy should take into account what "the people" believe, then, depends on whether people's beliefs matter for determining its subject matter. Only a view that holds that "the people" should have a say in what counts as liberty or equality would imply that the success conditions of political philosophy include sensitivity to public opinion. Such a position I take to be dead on arrival. Liberty is what it is. And no matter what attitudes a society might have, if it treats women as inferior to men, say, it violates the ideal of equality. ${ }^{3}$

\section{Who are "the people"?}

Suppose I'm wrong about that. Suppose what "the people" think really does determine what counts as liberty or equality or what have you. And suppose that means philosophers should take the views of "the public" very seriously in their work. That raises a further question: who are "the people"?

This is no easy question to answer. And it's often highly contested. (As de Shalit obviously knows.) But it matters a lot. Who the people are determines with who we are politically associated. Who the people are determines for who we are forced to bear certain burdens. Who the people are determines to whose desires government subjects us. And much, much more.

This raises a major problem for de Shalit's position. For who counts as "the people" is itself a philosophical question. As such, it cannot be fruitfully addressed by asking an (assumed) public for its views. When we ask the current inhabitants of a territory whether or not outsiders have a right to immigrate, we will already have taken a stand on that question (thus begging it in the process). We will have already decided that these people have a say in the matter of who counts, a say that the (assumed) "outsiders" lack. But that cannot be an innocent assumption. Indeed, it's one that desperately needs to be questioned.

In much philosophical work, who "the people" are figures simply as an assumption. Many theories take societies or nations as a given, asking how those societies ought to be governed. But just as a lot turns on this question practically, so too a lot turns on it philosophically. Asking who the people are has the potential to uproot much of standard political thought, and virtually

\footnotetext{
${ }^{3}$ This is not to say that the search for the truth rules out seeing generally held intuitions about moral cases, say, to have evidentiary value. That (much more modest) suggestion is neither De Shalit's point, nor what's in dispute here.
} 
all of common public sentiment. It may uproot theories of political obligation. ${ }^{4}$ It may uproot ideas about social justice. ${ }^{5}$ It, again, may uproot theories of immigration and global justice. ${ }^{6}$ Whether or not these ideas really should be uprooted ought to be a prime question in political philosophy.

\section{Philosophy and persuasion}

De Shalit seems animated by an aversion to philosophy that's academic in the pejorative sense. I share this aversion. Too much of our discipline investigates questions that are at best esoteric or irrelevant, at worst excuses to rack up publications. Two points are particularly well-taken. To find out what questions matter, we should be attuned to the problems and issues that appear in our lives, including our social lives. And to find out how best to ask those questions, we need a deep understanding of how our societies work. There is no disagreement between de Shalit and myself about this.

At times, de Shalit writes as if there is no conflict between a search for the truth and his conception of political philosophy. ${ }^{7}$ When discussing the traditional idea that philosophers should orient themselves toward the truth, he argues that:

[the] wish to prove that an argument is true should not be undermined if in addition [one] is socially or politically motivated to study this question.

As a general matter this is true, of course. One might be interested in social or political questions of the day, even consider those the most important ones, and then take it upon oneself to find out the truth about those questions. Again, there is no disagreement between us about this.

But that's not the important question here. What's important isn't whether such a position is possible in general, but whether it's possible given de Shalit's view that political philosophy is not just about the truth, but about persuasion.

Consider again de Shalit's proposal:

[P]olitical philosophy should indeed be conducted as a 'public' reflective equilibrium model, namely using not only the public's intuitions but also the public's theories.

Can it really be maintained that there are no trade-offs between truth-seeking and a program of persuasion using this method? Philosophy is a discipline of reason. We try to reconcile our initial views or intuitions with abstract principles we see reason to accept, rendering the whole of our beliefs internally consistent and as plausible as we might hope for.

\footnotetext{
${ }^{4}$ See e.g. A. John Simmons' "particularity requirement." See A. John Simmons, Moral Principles and Political Obligations, (Princeton University Press, 1979).

${ }^{5}$ Compare David Miller's discussion of social justice. See e.g. David Miller, Principles of Social Justice, (Harvard University Press, 1999).

${ }^{6}$ For several arguments to this effect, see Bas van der Vossen \& Jason Brennan, In Defense of Openness, (Oxford University Press, 2018).

7 Despite, and seemingly contradicting his "democratic" conception of political philosophy, de Shalit affirms a commitment to the traditional view I defend. For example, when de Shalit distinguishes philosophy from mere ideology, he writes: "What legitimizes their contributions [from a philosophical point of view] is that their theories are true, not that they represent certain interests or ideals in an eloquent or elegant manner."
} 
Clearly, such a discipline need not be particularly well-suited for producing persuasive views. Psychologists teach us that reason isn't great at persuading. What really sways people's opinions are appeals to emotion or sentiment. We need not go as far as saying that the emotional tail is wagging the rational dog. Perhaps reason is more than merely the faculty of making sound good what we're already emotionally predisposed to accept. On that view, it's reasoning rather than reason that moves the needle. And the persuasiveness of reasoning often doesn't hinge on its being internally consistent. ${ }^{8}$

Still, on any view, the thing that changes people's minds is rarely the philosophical quality of one's argument. It takes training to become receptive to that. The standards of success for persuasiveness of an argument do not coincide with its truth-value, then. It's one thing to know the right answer about something, quite another to persuade others of that answer. And saying the thing that's persuasive can require something quite different from saying what's true. Indeed, that's why de Shalit proposes his different conception of how political philosophy is to be done in the first place.

Becoming more persuasive can require incurring costs along the dimensions of reason and truth-seeking. To illustrate, consider once again the example of immigration. Suppose the truth about the ethics of migration supports, as I believe, open borders. This position, of course, has not exactly proven persuasive in our world. One of the safest ways to lose an election in virtually any country today is to advocate for more immigration. Yet, the position may be (is) true.

How might we persuade people of its truth, then? One effective approach would be to follow de Shalit's recommendation, and appeal to false, but widely held, premises. The case for open immigration doesn't hinge on its being good for the domestic economy. Yet, making the point that increased immigration in fact is good for the domestic economy will prove more persuasive than pointing out that (the non-existent) economic benefits of restricting immigration would not justify infringing the liberty of strangers. ${ }^{9}$

Might de Shalit say that arguing this way has no truth-costs? Arguments like this are conditional - they suggest that the case for open borders relies on its economic gains. But one can assert the truth of the conditional without asserting the truth of its antecedent. So why say that such an argument violates the demands of traditional political philosophy?

But this really is too cute. In putting forth an argument like this, the conversational implicature will be clear to everyone: the speaker will be commonly understood to be endorsing its premises. It's like saying that if immigration were economically harmful, that would suffice to show it unjust. And doing that really is harmful - however misguided in this particular context. It gives the false idea that societies can legitimately prioritize their own economic well-being at the (serious) costs of others a veneer of respectability it simply does not merit. Of course, endorsing true conclusions on the basis of false premises beats false conclusions on the basis of false premises. But we should set our sights higher than that.

In any case, even that task cannot be done without the truth. If we're supposed to persuade people, of what are we supposed to persuade them? Presumably of the things like how our society might be improved, say. But that, of course, requires that we first figure out what constitutes a true improvement. If we critique a society's institutions as (really) unjust, we are

\footnotetext{
${ }^{8}$ See Jonathan Haidt, The Righteous Mind, (Vintage Books, 2012)

${ }^{9}$ For supporting empirical evidence, see Van der Vossen \& Brennan, In Defense of Openness.
} 
thereby committing ourselves to the truth about justice mattering (a lot). And that truth may or may not be implied by "the public's theories."

\section{A spectrum}

On a purist version of de Shalit's proposal, political philosophy becomes a very peculiar branch of philosophy. If we take that proposal to its logical extreme - understanding political philosophy as purely about persuasion, using "the public's" theories and assumptions - it's no longer something done with an eye to the truth or reason. At that point, one might wonder if we're still engaged in political philosophy.

One might wonder, of course, whether this view can be thusly contained. I suspect that if de Shalit's arguments are sound, they would be sound for all of philosophy - indeed, all of science. And if that's the case, the public's views would have to become important data for all these questions. But I take it no one seriously maintains, say, that whether or not "the public" believes the earth is heating up matters for whether or not it is in fact heating up.

De Shalit isn't proposing such an extreme view, of course. Rather, the point is that there's a spectrum of approaches to political philosophy. At one end, there's the pure traditional conception, truth-seeking its sole aim. At the other, a pure version of de Shalit's proposal, its aim persuading the public using its theories and intuitions.

Points between those two extremes represent different trade-offs between the two goals, incurring some cost along one dimension in order to serve the other. Simplifying greatly, and assuming a constant rate, we can represent the trade-off as in Figure $1 .^{10}$

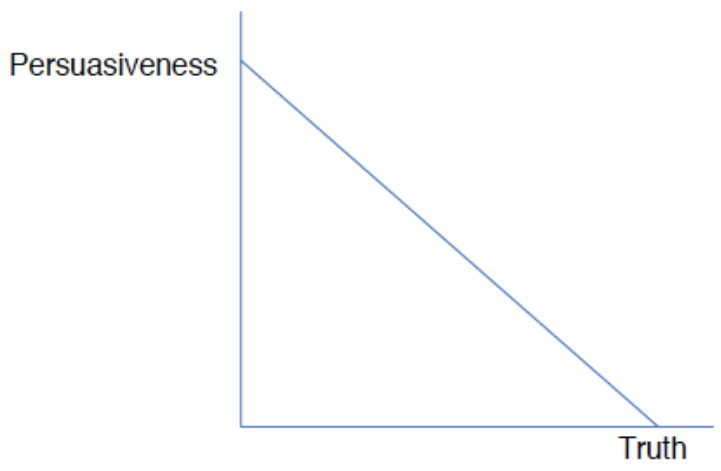

Figure 1

The trade-off here is one of aims. It need not be one of success. Hopefully the truth has some persuasive force in and of itself. And those who orient themselves toward pure persuasiveness may still end up spreading beliefs that are true. Still, the trade-off between aims is what's at stake here, and there's little reason to think there is no correlation between aiming at the truth and achieving it.

De Shalit's proposal implies sacrificing some truth-seeking in order to gain some persuasiveness. Is that acceptable? It depends. Two things are particularly important. First, there are the demands of the situation in which one finds oneself. Sometimes, the times are such as to demand more persuasion - sometimes, pure truth-finding is more important. Second,

\footnotetext{
${ }^{10}$ Obviously, there are more aims that philosophy might serve, posing different kinds of trade-offs. In reality, then, there is an n-dimensional choice space representing all trade-offs.
} 
there is the issue of one's relative abilities. Some people are better at being persuasive, others better at truth-finding.

Other things equal, the strength of the imperative to orient oneself toward persuasiveness over truth-finding roughly corresponds to the product of these two factors. To the extent that one finds oneself in more urgent circumstances, and to the extent that one is well-placed to help improve them, one becomes more permitted (perhaps required) to move away from pure philosophy.

The worry about de Shalit's argument thus isn't that he is willing to sacrifice truth-seeking for persuasiveness at all. Given the right circumstances, that can be the right approach. Rather, the worry is his ruling out that one might resist the trade-off. The pure version of the traditional conception of philosophy is important. Sometimes, for some people (I would say: most of the time, and for most of us) seeking the truth simpliciter is the right thing to do.

De Shalit labels this position narcissist:

I called this the Narcissist position, not because I believe that those holding it are narcissists, but because it sends the message that philosophy is pure and beautiful and should not engage in muck, i.e. argumentation in politics. Doing political philosophy is about judgement, whereas doing politics is about deciding what to do, and the two need not coincide.

Note that this argument presupposes that there indeed are trade-offs between persuasion and truth. But if there really are such trade-offs, and the truth must matter in the end, his proposal to orient political philosophy towards persuasiveness becomes deeply problematic. It sacrifices a valuable and worthwhile task.

\section{On impact}

Academics, de Shalit observes, often find themselves frustrated because "it is extremely difficult for them to make an impact on real life." One of de Shalit's motivations to orient political philosophy toward persuasion is to avoid this frustration. Perhaps persuading (if one is lucky) people on the street is more rewarding than knowing that one's published work is read by some of one's colleagues (if one is lucky).

Suppose political philosophers really are frustrated. So what? It's odd, to say the least, to call for a revision of how philosophy is done because one doesn't enjoy the way it ought to be done. No doubt, philosophy can be a psychologically taxing field (full of reminders of the limits of one's understanding, full of rejection, and more). At times, it can feel like a life no "normal" human being could enjoy. But that doesn't show that the discipline should be reformed. If anything, it shows that one should try to do a better job. Or, if that's not on the cards and one really cannot live with it, it shows that one ought to look for another job.

Must philosophers have impact? That might support requiring a persuasive approach like de Shalit's. ${ }^{11}$ But the desire to make an impact might be questioned, too. Personally, I think it's overrated. (It smacks, if I may be forgiven, of a kind of narcissism of its own.)

\footnotetext{
${ }^{11}$ Assuming, that is, that de Shalit's approach indeed promises to deliver more impact. That assumption might be questioned. Making impact one's goal need not actually deliver more impact.
} 
The desire to have an impact is the desire to shape the world in one's own image. Should we desire this? Perhaps not desiring impact should figure among the virtues characteristic of a liberal political outlook. Not desiring impact represents a kind of political humility - the recognition that one's views are but one among many and being happy to recognize one's place as just that. To live peacefully and respectfully among each other, we cannot all want to have an impact. And if we desire no one to have outsized political influence, that desire should include ourselves.

Most likely, the desire to have an impact stems from the desire to legitimate philosophical activity. Or perhaps, the desire to legitimate the considerable public expenditure in support of that activity. Impact is typically thought to have this legitimating force. Suppose we accept that thought (which I do not). Even then, it remains inappropriate for individual philosophers to feel much frustration about their lack of individual impact. The expectation on the part of society would be appropriate for the discipline of philosophy as a whole, not for individual philosophers.

Philosophy, if it is done correctly, is always important. After all the search for the truth is important. This is why unfree societies do not allow philosophy that seeks the truth, allowing only "philosophy" that caters to the public or the party or whatever. Genuine philosophy is too important to allow, in such societies. But if it is dangerous, it has an impact and is important. ${ }^{12}$

Sometimes individual philosophers of course do have a real impact. But even those who don't can still contribute to a field that makes progress, ever so slowly, toward the truth. That field forms the context in which those individually impactful philosophers produce their work. And the field as such plausibly has influence, too. (We can also have real impact on their students, something that's very much worth our time.)

That said, it's probably true that our discipline isn't as good at communicating its import to those who are not part of it. Academic philosophers do not excel at communicating their views, arguments, and findings to non-academics. We don't get paid to do that. What's more, like any professional discipline, the more advanced the field of political philosophy becomes, the less easily accessible it will be to the untrained. In itself, that isn't much of a problem. Just as there is a role for string theorists in physics and for those who communicate its relevance to the general public, so too there is a place for abstract work and more accessible work in political philosophy, including works that help disseminate otherwise abstract findings.

Of course, what those who make it their business to communicate philosophy to the general public should communicate is, once more, the truth. But that presupposes that there will be others who it their business to seek that truth. And so we've come full circle. Political philosophers should, like philosophy more generally, not give up the unqualified search for the truth.

\footnotetext{
12 I owe this point to John Thrasher.
} 